\title{
Effects of Corrective Feedback on the Acquisition of Chinese Directional Verb Compounds by Second Language Learners
}

\author{
Zhengwei Qiao \\ University of Iowa, Iowa City, USA
}

\begin{abstract}
Feedback promotes L2 (second language) development by making learners’ errors salient. Recent interest (Lyster \& Saito, 2010) has focused on how the effects of different types of feedback vary as a function of the complexity of the linguistic targets. This study examined the impact of implicit feedback (recasts) and explicit feedback (metalinguistic clues) on American students' acquisition of Chinese directional verb compounds, which express motion events in Chinese. Chinese and English frame motions events quite differently (Slobin, 2004), and recent research has focused on how L2 learners acquire the use of structures that possess significant differences from their L1s (first languages) (Chen \& Ai, 2010). Fifteen intermediate-level English learners of Chinese engaged in a picture description task. One group received implicit feedback on errors of the target structure, another received explicit feedback, and the control group received no feedback. The learners took a pretest, an immediate posttest, and a delayed posttest. Both experimental groups improved their performances on the intermediate posttest, whereas the control group did not. Moreover, the recast group retained its improvement on the delayed posttest, whereas the metalinguistic group lost their benefits on the delayed posttest. This finding indicates that both types of feedback may have short-term positive effects. One tentative explanation for the relatively longer benefits of recast is that it potentially helps learners internalize the target forms of which learners have limited knowledge (Lyster, 2004).
\end{abstract}

Keywords: corrective feedback, recasts, metalinguistic feedback, directional verb compounds

\section{Introduction}

The past decade has witnessed a noticeable increase of interest in the effects of corrective feedback on L2 (second language) learning. Corrective feedback can be used as a tool to help learners notice their interlanguage gap in their first output and therefore push them to reanalyze their utterance before their second output (Swain \& Lapkin, 2002). Corrective feedback contributes to L2 development by informing learners about the acceptability of their utterance and raising their awareness of language use (Long, 1996).

Recently, there has been increasing interest in whether different types of feedback have differential effects on L2 learning (Yang \& Lyster, 2010). The question of how the efficacy of different types of feedback interacts with the learners' readiness for the target structure remains to be examined. The present study investigates how recasts and metalinguistic feedback in communicative interaction may benefit L2 learners' acquisition of directional verb compounds in Chinese. Research of this type has not, to date, been conducted in Chinese grammar instruction. 


\section{The Role of Recasts and Prompts}

Recasts have been defined by Lyster and Ranta (1997) as "the teacher's reformulation of all or part of a student's utterance, minus the error” (p. 46). This definition emphasizes that recasts can involve either full reformulation or partial reformulation of learners' erroneous utterances. That is, the instructor implicitly reformulates all or part of the erroneous utterances without indicating to the learners that they have made an error. An example of recasts is illustrated in Example 1.

Example (1) Recast

Student: Why did you fell down?

Teacher: Why did you fall down?

Student: Fall down, yes. (Oliver \& Mackey, 2003)

Recasts are by far the most frequent feedback found in language classrooms (Lyster \& Ranta, 1997; Sheen, 2004). Recasts are frequently used in classrooms since the implicit meaning-focused nature of recasts ensures a flow of communication and at the same time draws learners' attention to their non-target-like utterances. In accordance with focus on form, recasts allow "teachers and students in task-based, content-based, sheltered subject matter, bilingual, and immersion classrooms" to "concentrate on nonlinguistic curricular content, their main concept, without worrying that language development will be impeded if they do not resort to intrusive, explicit "error correction" of the traditional kinds" (Long, 2007, p. 114). Thus from the psycholinguistic standpoint, recasts play a facilitative role in promoting language acquisition.

Recasts promote L2 development, because they provide learners with both positive evidence by modeling the target-like utterances, and negative evidence by reformulating learners' non-target-like utterances (Long, 1996). Yet, the negative evidence manifested in recasts is often overlooked by learners. One reason is that recasts tend to be ambiguous in discourse moves (Lyster, 1998). This is particularly evident in communicative classrooms, where learners pay more attention to the meaning of language rather than forms. For example, Lyster and Ranta (1997) reported that in immersion language classrooms or content-based classrooms, recasts were not distinguishable with non-corrective feedback such as confirmation of what the learners have said. Learners often overlooked the implicit feedback, and consequently rarely modified their output following recasts.

Different from recasts, which provide learners with correct forms, prompts withhold the correct forms by simply indicating to learners that they have made an error. Prompts include the corrective feedback such as metalinguistic clues, elicitation, clarification requests, and repetition of errors. They are also called "self-repair", since they do not provide learners with correct forms but encourage learners to repair their errors. In contrast, explicit correction and recasts are also called "other-repair" since the target-like form is provided to learners in the interlocutor's feedback. Both other-repair and self-repair fall along a continuum of explicitness, with recasts situated in implicit end of corrective feedback leading to other-repair. By contrast, metalinguisitic feedback is situated in the explicit end of feedback involving self-repair. Thus, recasts constitute the best exemplar of implicit feedback, while metalinguistic feedback constitutes the best exemplar of explicit feedback (Ellis, Loewen, \& Erlam, 2006).

Prompts facilitate L2 learning since they elicit pushed output (or self-repair) from the learners. According to Swain's (1995) Output Hypothesis, learners need to be pushed to make use of their language resources and stretch their interlanguage. When learners are pushed to express an idea in L2, they get to notice what they can do and cannot do in their current language system, and this awareness pushes them to strive for greater accuracy (Swain, 1995). Pushed output also provides opportunities for deeper L2 syntactic processing, because 
"output may stimulate learners to move from the semantic, open-ended, strategic processing prevalent in comprehension to the complete grammatical processing needed for accurate production” (Swain, 2000, p. 99). In the case of recasts, however, learners' modified output is not required. If learners do follow up with a response after recasts, it is not clear whether learners simply imitate what the instructor has said or they have noticed the corrective intention of recasts.

Classroom quasi-experimental studies have generally presented a superiority of prompt over recasts. Ellis et al. (2006), for example, investigated the relative effects of metalinguistic explanation (i.e., a prompt consisting of repetition of the error followed by a clue such as you need past tense) and recasts on the acquisition of English past tense -ed. The participants in Ellis et al.'s (2006) were 34 lower-intermediate L2 learners who were asked to narrate short stories based on a sequence of pictures with the target structures. The measures included oral imitation tests (designed to measure implicit knowledge) and an untimed grammaticality judgment test and a metalinguistic knowledge test (both designed to measure explicit knowledge). Statistical analysis of the learners' performance on the posttests showed an advantage for the metalinguistic explanation over recasts for both the oral imitation test and grammaticality judgment test. Results showed that overall the metalinguistic explanation benefited both implicit and explicit knowledge (Ellis et al., 2006).

Although classroom quasi-experimental studies have shown that prompt is superior to recasts in form-focused instruction, not all prompts necessarily work better than recasts. McDonough (2007), for example, designed an empirical study assessing the impact of recasts and clarification requests on the emergence of simple past activity verbs in English. Clarification requests were operationalized as "open-ended requests for clarification, such as 'huh?', 'pardon?', 'what?', 'again?’” (p. 329). The results showed that learners in both groups achieved similar gains on the posttests. The findings suggested that by simply eliciting self-repair or pushed output, clarification requests did not necessarily result in greater gains than recasts, which assist learning with positive evidence. In another study that compared clarification requests and recasts in dyadic interaction, Lyster and Izquierdo (2009) investigated the acquisition of grammatical gender by adult L2 learners of French. Students first received classroom instruction on the target structures, and then they were exposed to form-focused instructional treatment in the laboratory setting. Contrary to the expectation that the clarification request group would outperform the recasts group, because clarification request provides opportunities for self-repair, both groups equally improved accuracy in the target form over time (Lyster \& Izquierdo, 2009).

\section{Directional Verb Compounds in Mandarin Chinese}

The target form of the present is directional verb compound. Verbal compounds are highly productive in Chinese and widely used in both speech and writing. Directional Verb Compounds (henceforth DVCs) are common forms used to encode a motion event, as illustrated in Example 2.

$$
\begin{array}{rlll}
\text { Example (2) Zhangsan } & \text { zou-jin } & \text {-le } & \text { jiaoshi } \\
\text { Zhangsan } & \text { walk-enter } & \text {-PERF } & \text { classroom } \\
\text { "Zhangsan walked into } & & \text { the classroom." }
\end{array}
$$

Mandarin DVCs usually consist of two or three root verbs: V1V2. V1 is usually an action verb indicating the cause or motion, and V2 is a stative verb or an action verb indicating a change of state or a change of location. The following is a set of commonly used directional verb complements (which occupy the second verb slot in DVCs) in Mandarin (see Example 3): 


$\begin{array}{rlllll}\text { Example (3) chu } & \text { "exit” } & \text { OUT } & \text { jin } & \text { “enter” } & \text { IN } \\ \text { xia } & \text { "descend” } & \text { DOWN } & \text { guo } & \text { "pass” } & \text { PAST-CROSS } \\ \text { hui } & \text { "return” } & \text { BACK } & \text { kai } & \text { “open” } & \text { AWAY } \\ \text { qi } & \text { "rise” } & \text { UP } & \text { shang } & \text { “ascend” } & \text { UP }\end{array}$

These directional verb complements have some specific functions. First, all of them can function alone as independent verbs. Second, all of them can be immediately followed by a deictic path verb (e.g., lai2 "come” and qu4 "go").

DVCs in Chinese are chosen as the target of the current study for two reasons. First, even though the DVCs are introduced to the students from the first year, learners demonstrated great difficulty in gaining full control of the structure, even at intermediate and advanced levels (Wu, 2010). Second, English and Chinese are typologically different in terms of motion event expression. Chinese and English frame motions events quite differently (Slobin, 2004), and recent research has focused on how L2 learners acquire the use of structures that possess significant differences from their L1s (first languages) (Wu, 2010).

\section{Typological Difference Between Chinese and English}

Languages are different typologically in how space and motion events are expressed (Talmy, 2000). According to Talmy (2000):

[T]he basic Motion event consists of one object (the Figure) moving or located with respect to another object (the reference object or Ground). A motion event can be associated with an external co-event that most often bears the relation of Manner or of Cause to it. (pp. 25-26)

It is therefore suggested that a motion event may have six components:

Figure: an object moving or located with respect to another object (ground);

Ground: a reference object in relation to which the figure moves;

Path: trajectory or site occupied by the figure;

Motion: presence per se of motion of locatedness in the event;

Manner: the particular way the motion is performed;

Cause: the efficient origin of a change in motion or location. (Talmy, 2000, p. 26)

Talmy (2000) proposed a motion-event language typology: satellite-framed languages (henceforth S-languages) and verb-framed languages (henceforth V-languages) depending on how the path is encoded for events involving movement. Spanish, French, Hebrew, and Turkish are typical V-languages, and English, German, Dutch, Mandarin, and Russian are typical S-languages.

Mandarin Chinese, a serial-verb language, was initially treated as an S-language (Talmy, 1985). Given that in serial-verb languages, there is a closed set of path verbs, Talmy considered the main verb to be the manner verb and the path verb to be a satellite. In Berman and Slobin's (1994) study, however, they found that $40 \%$ of Chinese speakers use the construction "fei chu" ("fly exit") to describe the owl's emergence scene, as in Example 4. Note that both "fei” (“fly") and "chu” ("exit”) can function as independent verbs. Thus, different from English in which path is usually expressed with participles or adverbs, path is usually expressed with verbs in Chinese. The findings pose challenges for Talmy’s binary typological classification.

$$
\begin{aligned}
& \text { Example (4) Mandarin: Fei chu yi-zhi maotouying. } \\
& \text { "Fly out one-CL owl." }
\end{aligned}
$$


Slobin (2004) then proposed a revised motion-event language typology: V-languages, S-languages, and equipollently-framed languages (henceforth E-languages). They differ in the means of path expression. In V-languages, path is expressed by a verb, with subordinate expression of manner. The typical construction type includes path verb + subordinate manner verb. In S-languages, however, path is expressed by a non-verbal element associated with a verb. The typical construction type is manner verb + path satellite. In E-languages, path and manner are expressed by equivalent grammatical forms, as shown below (see Example 5):

Example (5) $\underline{\text { S-languages }}$

English: The man ran into the house.

V-languages

Spanish: El hombre entró corriendo a las casa.

The man entered running to the house

E-languages

Mandarin: zhege nanren pao-jin-le fangzi.

The man run-enter-LE house

"The man ran into the house."

\section{L1 Thinking in L2 Speaking}

Talmy's typological analysis has received empirical support from acquisition studies investigating how speakers of typologically different languages exhibit different grammars of discourse. Berman and Slobin (1994), for example, examined the influences of typological difference on L1 acquisition, and found that speakers of different language types tend to express motion events differently. As an illustration, speakers of S-language used a greater variety of motion verbs and tended to provide more manner information and more path information than did speakers of V-languages. Hence speakers' established linguistic patterns have an effect on how they talk about event, and this tendency may carry over to secondary languages. Based on the observation that a child learns particular ways of thinking for speaking in acquiring a native language, Slobin (1996) proposed:

Thinking for speaking, which refers to the language-induced tuning of attention to different aspects of situations that one's language routinely encodes. This involves picking those characteristics of objects and events that: (1) fit some conceptualization of the event, and (2) are readily encodable in the language. (p. 76)

According to his proposal, languages differ in their thinking for speaking, and the differences influence thoughts in different ways. A speaker' conception is restricted by established linguistic patterns.

Slobin (1996) further argued that there is also "first language thinking in second language speaking". That is, L2 learners are influenced by their native language grammar discourses when speaking L2. Slobin (1996) pointed out that "each native language has trained its speakers to pay different kinds of attention to events and experiences when talking about them. This training is carried out in childhood and is exceptionally resistant to restructuring in adult second-language acquisition” (p. 89). Slobin's L1 thinking in L2 speaking is supported by the findings in studies investigating the influences of the learners' native languages on their L2 acquisition, which has shown that if learners' native languages and the languages they are studying are typologically different, then the difference may cause them to express themselves differently even when they are advanced L2 learners (Stam, 2001). 


\section{The Present Study}

\section{Research Questions}

The relationship between instructional input and learning outcomes of Chinese DVCs is an important issue in Chinese pedagogy. Given the mixed results generated from empirical studies, it still remains a question as to how the effects of recasts and prompt can be mediated by linguistic structures. As suggested by Ellis (2007), future research needs to determine "how linguistic factors may determine when different types of feedback will work for acquisition” (p. 360). The purpose of this study is to contribute to this body of work by investigating the relative effects of two corrective feedback moves-recasts and metalinguistic clues—on L2 learners' acquisition of DVCs. The following research questions were addressed: (1) Can both recasts and prompt (e.g., metalinguistic clues) promote learners' acquisition of Chinese DVCs?; and (2) Which type of corrective feedback has a longer positive effect in assisting learners to use the target structures?.

\section{Participants}

This study was conducted in a large, public university in the United States. Fifteen students, who were taking the second-year Chinese course, participate in the study. They were classified as intermediate or intermediate low students according to their previous Chinese test scores. Participants were randomly assigned to one of the two treatment options (recast group $=5$ students, metalinguistic group $=5$ students) or the control group option (control group $=5$ students) $($ see Table 1$)$.

Table 1

Number of Partipants and Average Months of Their Studying Chinese

\begin{tabular}{lll}
\hline Group & Number of participants & Average months of studying Chinese \\
\hline Controls & 5 & 24 \\
Recast & 5 & 24 \\
Metalinguistic & 5 & 24 \\
\hline
\end{tabular}

\section{Operation of Recasts and Metalinguistic Feedback}

Recasts were operationalized as "a teacher's reformulation of a student's erroneous utterance, without changing the meaning of the student's original utterance, in the context of a communicative activity" (Sheen, 2006, p. 307). The recasts used in the current study were typically declarative, short recasts involving only one change. As argued by Sheen (2006), this type of recasts is more likely to promote noticing, and therefore more likely to be perceived by the learners. In the current study, metalinguistic feedback was chosen as an example of prompt since it constituted the best exemplar of explicit feedback, which was in contrast with recasts, which constituted the best exemplar of implicit feedback (Ellis, 2006). It was operationalized as a teacher's repetition of learners' errors, followed by metalinguistic clues such as "you need a directional verb compound” (Lyster \& Ranta, 1997; Lyster, 2004; Ellis et al., 2006). The learners received corrective feedback on their errors when they performed communicative activities with the researcher. One group received recasts and the other group received metalinguistic feedback on their errors of the target structure. The control group only received feedback on the content of their description.

\section{Data Collection Procedures}

The instructional treatment consisted of two 30 minutes session over a period of two weeks. Prior to the 
study, the textbooks of students were reviewed to ensure that the vocabulary used in the practice session is appropriate to students' proficiency level. After taking the pretests, learners were randomly assigned to three groups-recasts group, metalinguistic group, and the control group. During the treatment, all three groups carried out a picture-cued description activity with the instructor (see Table 2).

Table 2

Design and Timeline

\begin{tabular}{|c|c|c|c|c|}
\hline Week 1 & Week 2 & Week 3 & Week 4 & Week 6 \\
\hline Pretest & Treatment & Treatment & Posttest & Delayed posttest \\
\hline
\end{tabular}

\section{Testing Instruments and Procedures}

One week prior to the instructional treatments, the participants signed consent forms. Students' performance on Chinese DVCs were measured by three tests: pretest, posttest after the treatment, and delayed posttest two weeks after the treatment. Each test session consisted of an oral picture description task.

\section{Materials and Methods}

Treatment: Picture-cued description activity. Each learner participated in a one-on-one interaction with the researcher. They were given several sets of picture depicting actions that would elicit the use of Chinese DVCs. Some pictures were accompanied with verb lists to assist learners' performance. The researcher asked the learners what is happening with the woman or man depicted in the pictures. Before carrying out the task, learners were given a couple of minutes to plan for the story narration. They were also told to carefully prepare their recounts of the story, because they would be asked to provide as much detail as possible.

Coding of interaction. Oral interaction during the treatment was identified following the three-part sequence identified by Oliver (1995): NNS (non-native speaker) initial turn, NS (native speaker) response, and NNS reaction. The NNS initial turn was either target-like or non-target-like or an incomplete utterance. NS interactional moves were classified into the two major types of feedback (recast and metalinguistic explanation). The followings were some learners' responses to NS interlocutor's feedback (see Example 6).

Example (6) Learner: Ta shi shang suipian.

He picked the pieces.

Researcher: Ta shi qi suipian.

He picked up the pieces.

Learner: Shi qi suipian. Yes. Ranhou ta zhao-le yige xin beizi.

(He) Picked up the pieces. Then he found a new cup.

In the above example, it was clear that the learner wanted to use a DVC to describe the action but he used an incorrect verb complement (the second verb of a DVC). At this point, the native speaker intervened by reformulating his utterance. This feedback resulted in a successful change in the learner's performance.

Learners in the other experimental group received the corrective feedback in the form of metalinguistic feedback. Learners in metalinguistic group had been instructed about the linguistic terms including the term regarding DVCs. The following is an example of metalinguistic feedback (see Example 7).

Example (7) Learner: Ta zou louti.

He walked the stairs. 


\section{Researcher: Ta zou louti? You need a verb compound here}

He walked the stairs?

\section{Learner: Ta zou louti shang.}

He walks stairs up.

In this instance, the learner was uncertain how to form the verb compounds and did not understand how to use it appropriately. For instance, he used single verb zou ("to walk") initially. At this point, the native speaker pointed out the location of the problem. However, this metalinguistic explanation failed to move the learner any closer to the correct form. He was unaware that the location words should occur after a DVC. This showed that his knowledge of verb compound was still vague and he was not clear about the rules of forming the verb compounds.

Learners in the control group carried out the same picture-description tasks with the researcher. However, different from the two experimental groups, the feedback focused on their content of descriptions rather than on a particular grammatical structure.

\section{Tests: Oral Production Task}

The oral production task required learners to tell a story based on a series of pictures and word cues. Learners were asked to describe the pictures with the help of word cues. Each set of pictures elicited several target strucutures. Given that oral picture description task is designed to elicit learners' implicit knowledge, planning time is not provided to learners after they are assisted with the word cues (Ellis, 2005).

Two versions of oral tests (A and B) were created. To control for test-retest effects, learners would not take the same test in a row. For example, people might take the tests in the sequence of ABA or BAB, rather than AAB or BBA. Also to avoid memory effect, the sequences of test items in one test would be shuffled when learners take the same posttest after the treatment.

\section{Results}

Descriptive statistics on the use of the target structures for the three groups on all three tests were calculated (see Table 3). The learners' correct use of target structure was assessed by calculating the mean proportions of verb compounds. Each correct use of the target structure was allocated a score of 1. Each incorrect use of the target structure was given a score of 0 . Scores were computed as percentage correct. For example, if a test induced 10 test items and a learner got two of them correct, then this learner' s score was 0.2. If they made errors on structures other than the target structure, these errors were ignored for this study. If results showed that there existed differences among the groups on any of the three tests, then the pairwise $t$-tests were used to test whether the differences on the tests were statistically significant.

Table 3

The Mean Proportion of Target Structures on Prestest, Posttest, and Delayed Posttest

\begin{tabular}{llll}
\hline \multirow{2}{*}{ Group } & Pretest & Posttest & Delayed posttest \\
& $\mathrm{M}$ & $\mathrm{M}$ & $\mathrm{M}$ \\
\hline Controls $(\mathrm{n}=5)$ & 0.157 & 0.204 & 0.188 \\
Recast $(\mathrm{n}=5)$ & 0.176 & 0.602 & 0.444 \\
Metalinguistic $(\mathrm{n}=5)$ & 0.4 & 0.665 & 0.47 \\
\hline
\end{tabular}

The descriptive statistics for verb compounds on the Oral Production Task showed a range in overall 
accuracy from $15.7 \%$ to $40 \%$ on the pretest. Since learners were randomly assigned to different treatment groups, it turned out that the metalinguistic group happened to be stronger than the recast group at the onset of the study. To cure this problem, the author adopted ANCOVA (analysis of covariance), a statistical method, to adjust the unequal scores of two experimental groups at the commencement of the study.

Overall, the learners scored a mean of $24 \%$ on verb compound for the picture description task, which suggested that all of the learners initially had only limited knowledge of Chinese verb compounds, since their average mean was very low (24\%). It was also noticeable that score increased on the posttest for the recast group were higher than that for the metalinguistic group. Thus, the posttest scores can be interpreted as showing that the two types of feedback both led to gains on their acquisition of the target structures.

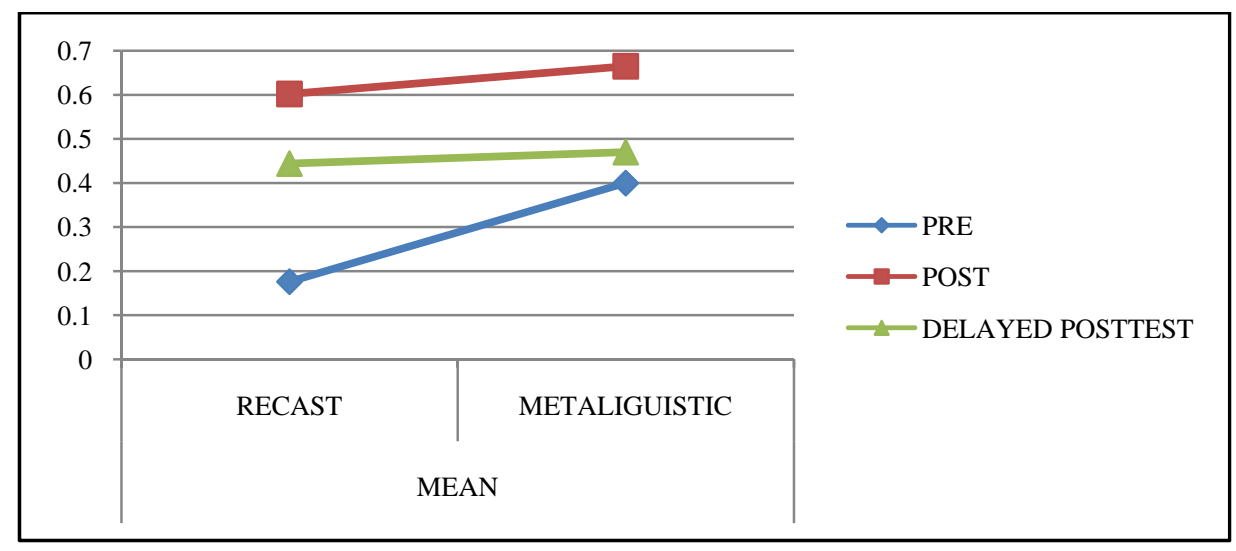

Figure 1. Test scores of target structures by the recast group and the metalinguistic group.

Figure 1 represents the test scores by the two experimental groups on the three tests. For the posttest, the recast group and the metalinguistic group each showed an increase in their correct use of verb compounds. To estimate the degree of using verb compound achieved over time by each group on the three tests, the disparity between the use of target structure on the pretest and the use of target structure on the two posttests was obtained. Even though the recast group gained more over this period, the pairwise $t$-test did not reveal any experimental group differences on their increase from the pretest to the posttest $(p<0.1)$. On the delayed posttest, they both exhibited a drop in their use of the target structures. However, the metalinguistic group demonstrated a sharper drop than the recasts group. The pairwise $t$-test revealed that the recast group sustained its significant improvement on both posttests, while the metalinguistic group has lost its advantage on the delayed posttest $(p<0.1)$. That suggested that the recast exhibited a positive effect longer than the metalinguistic explanation.

With respect to question one-whether the two experimental groups had a short-term effect on the acquisition of the target structure- the answer was positive. The control group did not gain greater control over the target structure, while the two experimental groups' scores increased significantly on both posttests. That suggested that both recasts and prompts have a short-term effect on the acquisition of grammatical structures.

With respect to question two, which asked which group sustained a longer positive effect in assisting learners to use the target structures, the answer was recasts group. How can we explain that recast sustained its benefits over the test times? For this study, even though the learners had some prior knowledge of the target structure, it was obvious their knowledge was very limited based on their scores on the pretest. DeKeyser's 
(1993) study indicated that when learners' proficiency was taken into account, the more explicit feedback was of greater benefit to the more able students. The present study found that simply providing the metalinguistic information might not be very helpful for low intermediate learners of Chinese to retain the target form effectively. L2 research has provided some evidences showing that grammar acquisition is susceptible to the effect of recast. For example, Long (1996) summarized aspects of L2 development that are theoretically susceptible to the influence of recast as the followings: vocabulary, morphology, language-specific syntax, and certain specifiable L1-L2 contrasts. This study confirms Long's hypotheses, given that the target structure for the present study was morphosyntactic grammatical form.

\section{Discussion}

The present study examined the relationships between L2 development and the types of feedback (recasts versus metalinguistic feedback) on American students' acquisition of Chinese verb compounds. The results of the present study have shown that the type of feedback the students get (implicit or explicit) had differential effects, depending on the learners' knowledge of the target forms.

The findings of the present study suggest that the differential effects of recasts and metalinguistic feedback were further mediated by learners' knowledge of the target forms. Researchers have argued that the learners' knowledge of the target forms plays a crucial role in determining the effectiveness of corrective feedback. Indeed, Ellis (1997) and other scholars (Bialystok \& Sharwood Smith, 1995) have pointed out that there are two types of acquisition. One type of acquisition occurs when target forms are internalized and other type occurs when learners have gained more control of internalized items. Recasts, by providing positive evidence to learners, can facilitate the internalization of the target forms. Metalinguistic feedback, which elicits modified output, can help learners to gain more control of the internalized items (Lyster, 2004). In other words, in order to benefit from metalinguistic feedback, learners need to have substantial knowledge of the target forms. However, given that learners in the current study had very limited knowledge of DVCs, as shown by their very low score on the pretest (24\%), it is not surprising that recasts have a longer positive effect than metalinguistic feedback in the current study.

The take-away lesson for teachers was that it would be helpful to vary their choices of feedback, since students even in the same class may be at different stages of acquisition and, thus, may react differently to different types of corrective feedback. This study helps us to establish the effects or effectiveness of L2 explicit instruction on the acquisition of Chinese verb compounds, especially considering the fact that very few studies have examined the correlation between input and learning outcomes for L2 acquisition of the construction under investigation. Specifically, the fine-grained analysis reveals that some types of instruction are more advantageous for certain proficiency level than others, and provides empirical evidence for the relationship between corrective feedback and learners' readiness for the target forms.

As in all empirical studies on language acquisition, there were inevitable limitations. First, the small sample size of the study allowed for only tentative conclusions. However, since each participant interacted with the instructor for several times over the period of study, the repeated measure methods indeed increase the statistical power of the study. Second, the length of the treatments was rather short (approximately one hour). It is possible that with a longer treatment, metalinguistic feedback would have proved more effective. Third, the target structure for the author's study was restricted to Chinese DVCs. Actually, there are a number of other 
verb compounds in Chinese including resultative verb compounds, potential verb compounds and descriptive verb compounds. In future studies, the author would like to investigate a wider range of verb compounds to see whether the present study can be generalized to those structures.

\section{References}

Ammar, A., \& Spada, N. (2006). One size fits all? Recasts, and L2 learning. Studies in Second Language Acquisition, 28, 543-574.

Berman, R. A., \& Slobin, D. I. (1994). Development of linguistic forms: English. In R. A. Berman \& D. I. Slobin (Eds.), Relating events in narrative: A crosslinguistic developmental study. Hillsdale, N.J.: Lawrence Erlbaum Associates.

Bialystok, E., \& Sharwood Smith, M. (1985). Interlanguage is not a state of mind: An evaluation of the construct for second language acquisition. Applied Lingusitics, 6, 101-117.

Chen, J., \& Ai, R. (2010). Encoding motion and state change in L2 Mandarin. In The Proceedings of the 21st North American Conference on Chinese Linguistics (pp. 149-164), Smithfield, R.I..

DeKeyser, R. M. (1993). The effect of error correction on L2 grammar knowledge and oral proficiency. Modern Language Journal, 77, 501-514.

Ellis, N. C. (1994). Introduction: Implicit and explicit language learning-An overview. In N. C. Ellis (Ed.), Implicit and explicit learning of language (pp. 1-31). San Diego, C.A.: Academic Press.

Ellis, R. (1997). SLA research and language teaching. Oxford: Oxford University Press.

Ellis, R. (2005). Measuring implicit and explicit knowledge of second language: A psychometric study. Studies in Second Language Acquisition, 27, 141-172.

Ellis, R. (2006). Researching the effects of form-focused instruction on L2 acquisition. AILA Review, 19, 18-41.

Ellis, R. (2007). The differential effects of corrective feedback on two grammatical structures. In A. Mackey (Ed.), Conversational interaction in second language acquisition: A collection of empirical studies (pp. 339-267). Oxford: Oxford University Press.

Ellis, R., Loewen, S., \& Erlam, R. (2006). Implicit and explicit corrective feedback and the acquisition of L2 grammar. Studies in Second Language Acquisition, 28, 339-368.

Han, Z. (2002). A study of the impact of recasts on tense consistency in L2 output. TESOL Quarterly, 36, 543-572.

Iwashita, N. (2003). Negative feedback and positive evidence in task-based interaction. Studies in Second Language Acquisition 25, 1-36.

Leeman, J. (2003). Recasts and second language development: Beyond negative evidence. Studies in Second Language Acquisition, 25, 37-63.

Li, Y. (1990). On V-V compounds in Mandarin. Natural Language \& Linguistic Theory, 8, 177-207.

Lightbown, P. M., \& Spada, N. (1990). Focus-on-form and corrective feedback in communicative language teaching: Effects on second language learning. Studies in Second Language Acquisition, 12, 429-448.

Lightbown, P. M., \& Spada, N. (1994). An innovative program for primary ESL in Quebec. TESOL Quarterly, 28, 563-573.

Long, M. H. (1996). The role of the linguistic environment in second language acquisition. In W. C. Ritchie \& T. K. Bhatia (Eds.), Handbook of second language acquisition (pp. 413-468). San Diego, C.A.: Academic Press.

Long, M. H. (2007). Problems in SLA. Mahwah, N.J.: Lawrence Erlbaum Associates.

Lyster, R. (1998). Negotiation of form, recasts, and explicit correction in relation to error types ad learner repair in immersion classrooms. Language learning, 48, 183-218.

Lyster, R. (2004). Differential effects of prompts and recasts in form-focused instruction. Studies in Second Language Acquisition, 26, 399-432.

Lyster, R., \& Izquierdo, J. (2009). Prompts versus recasts in dyadic interaction. Language Learning, 59, 453-498.

Lyster, R., \& Ranta, L. (1997). Corrective feedback and learner uptake: Negotiation of form in communicative classrooms. Studies in Second Language Acquisition, 19, 37-66.

Lyster, R., \& Saito, K. (2010). Interactional feedback as instructional input: A synthesis of classroom SLA research. Language, Interaction and Acquisition, 2, 276-296.

Mackey, A. (1999). Input, interaction and second language development: An empirical study of question formation in ESL. Studies in Second Language Acquisition, 21, 471-497.

Mackey, A., Gass, S., \& McDonough, K. (2000). How do learners perceive interactional feedback?. Studies in Second Language Acquisition, 22, 471-497. 
McDonough, K. (2007). Interactional feedback and the emergence of simple past activity verbs in L2 English. In A. Mackey (Ed.), Converstaional interaction in second language acquisition: A collection of empirical studies. Oxford: Oxford University Press.

Oliver, R. (1995). Negative feedback in Child NS-NNS conversation. Studies in Second Language Acquisition, 17, $459-481$.

Oliver, R., \& Mackey, A. (2003). Interactional context and feedback in child ESL classrooms. The Modern Language Journal, 87, 519-533.

Sheen, Y. (2004). Corrective feedback and learner uptake in communicative classrooms across instructional settings. Language Teaching Research, 8, 263-300.

Sheen, Y. (2006). Corrective feedback, individual differences and the acquisition of articles by second language learners (Unpublished doctoral dissertation, University of Nottingham).

Slobin, D. I. (1996). From “thought and language” to “thinking for speaking”. In J. Gumperz \& S. Levinson (Eds.), Rethinking linguistic relativity (pp. 70-96). Cambridge: Cambridge University Press.

Slobin, D. I. (2003). Language and thought online: Cognitive consequence of linguistic relativity. In D. Gentner \& S. Goldin-Meadow (Eds.), Language in mind: Advances in the study of language and thought (pp. 157-192). Cambridge, M.A.: MIT Press.

Slobin, D. I. (2004). The many ways to search for a frog: Linguistic typology and expression of motion events. In S. Stomqvist \& L. Verhoeven (Eds.), Relating events in narrative: Typological and contextual perspectives (pp. 219-257). Mahwah, N.J.: Erlbaum.

Stam, G. (2001). Gestures and second language acquisition. Paper presented at TESOL Convention, St. Louis, Missouri, March.

Swain, M. (1995). Three functions of output in second language learning. In G. Cook \& B. Seidlhofer (Eds.), Principle and practice in applied linguistics: Studies in honour of H. G. Widdowson. Oxford: Orford University Press.

Swain, M. (2000). French immersion research in Canada: Recent contributions to SLA and applied linguistics. Annual Review of Applied Linguistics, 20, 199-212.

Swain, M. (2005). The output hypothesis: Theory and research. In E. Hinkel (Ed.), Handbook of research in second language teaching and learning. Mahwah, N.J.: Lawrence Erlbaum.

Swain, M., \& Lapkin, S. (2002). Talking it through: Two French immersion learners' response to reformulation. International Journal of Educational Research, 37, 285-304.

Talmy, L. (1985). Lexicalization patterns: Semantic structure in lexical forms. In T. Shopen (Ed.), Language typology and syntactic description III: Grammatical categories and the lexicon (pp. 57-149). Cambridge: Cambridge University Press.

Talmy, L. (2000). Toward a cognitive semantics: Typology and process in concept structuring (Vol. II). Cambridege, M.A.: MIT Press.

Wu, S. (2010). Learning to express motion events in an L2. Language Learning, (1), 1-41.

Yang, Y., \& Lyster, R. (2010). Effects of form-focused practice and feedback on EFL learners' acquisition of regular and irregular past-tense forms. Studies in Second Language Acquisition, 32, 235-263. 